\title{
Validasi International Prostate Symptom Score Versi Bahasa Indonesia pada Penderita Lower Urinary Tract Symptoms di Poliklinik Urologi RSUP Prof. Dr. R. D. Kandou Manado
}

\author{
${ }^{1}$ Stephanus J. Ch. Tangel , ${ }^{2}$ Alwin Monoarfa, ${ }^{2}$ Richard A. Monoarfa
}

\author{
${ }^{1}$ Program Studi Ilmu Bedah Fakultas Kedokteran Universitas Sam Ratulangi Manado \\ ${ }^{2}$ Divisi Bedah Urologi Bagian Ilmu Bedah Fakultas Kedokteran Universitas Sam Ratulangi- \\ RSUP Prof. R. D. Kandou Manado \\ Email: stephanuscharles@gmail.com
}

\begin{abstract}
Lower urinary tract symptoms (LUTS) due to BPH frequently occur in elderly men. Indonesian version of International Prostate Symptom Score (IPSS-Ina) is commonly used in the hospitals in Indonesia, including Prof. Dr. R. D. Kandou Hospital in Manado. However, there is still no study about IPSS-Ina validation in Manado. This study was perfomed by giving IPSS-Ina questionnaire to two sample groups, the treatment and the control groups. IPSS validation was tested by correlating the IPSS score and quality of life score. Reliability of IPSS-Ina was also tested by using internal consistancy test and test-retest to the two groups. There were 50 patients that fulfilled the inclusion and exclusion criteria, divided into the two groups as mentioned before. The oldest patients was 67 years in the treatment group, and the youngest one was 21 years in the control group. The Pearson correlation test showed that all correlations had $P$ values $<0.05$, therefore, all 8 questions in the IPSS-Ina used in patients not yet treated with TURP were valid. The Cronbach test showed that the 8 questions had realibility of 0.93 , which meant that the 8 questions translated into Indonesian had very high consistancy. The $t$ test of treatment group before and after TURP resulted in $\mathrm{t}=11.221$ and a $P$ value $<0.001$. Conclusion: IPSS-Ina has very good validation and reliability to people in Manado. Therefore, it has similar purpose, intention, and function to WHO version, and it has sensitivity to the changes of symptoms and signs of BPH patients before and after TURP.
\end{abstract}

Keywords: IPSS, LUTS, validation, BPH

\begin{abstract}
Abstrak: Lower urinary tract symptoms (LUTS) akibat BPH sering terjadi pada laki-laki usia lanjut. International Prostate Symptom Score (IPSS) versi bahasa Indonesia sudah banyak digunakan di berbagai rumah sakit di Indonesia, termasuk RSUP Prof. Dr. R. D. Kandou Manado. Penelitian ini bertujuan untuk memvalidasi IPSS versi bahasa Indonesia di Manado. Penelitian dilakukan dengan memberikan kuesioner IPSS versi bahasa Indonesia (IPSS-Ina) kepada dua kelompok subyek, yaitu kelompok uji dan kontrol. Validasi IPSS diuji dengan mengorelasikan hasil skor IPSS yang didapat dengan skor kualitas hidup (Quality of Life). Reliabilitas IPSS-Ina diuji melalui dua cara yaitu dengan uji konsistensi internal dan uji test-retest pada kelompok subyek. Hasil penelitian mendapatkan 50 pasien yang memenuhi kriteria inklusi dan eksklusi penelitian, dibagi menjadi dua kelompok (uji dan control). Usia tertinggi 67 tahun pada kelompok uji, dan terendah 21 tahun pada kelompok kontrol. Hasil uji korelasi Pearson mendapatkan semua nilai korelasi memiliki nilai $P<0,05$, jadi ke 8 pertanyan yang terdapat dalam IPSS-Ina yang digunakan pada pasien yang belum mendapatkan terapi TURP ialah valid. Hasil uji Cronbach memperlihatkan ke 8 pertanyaan ini memiliki reliabiltas sebesar 0,93 , yang berarti ke 8 pertanyaan skoring BPH dari WHO yang diterjemahkan ke dalam bahasa Indonesia memiliki konsisten yang sangat tinggi. Hasil uji t pada kelompok uji sebelum dan setelah menjalani tindakan TURP memperoleh $\mathrm{t}=11,221$ dengan $P<0,001$. Simpulan: IPSS versi bahasa Indonesia terbukti memiliki validitas dan reliabilitas yang sangat baik terhadap masyarakat di Manado, sehingga dapat dijamin memiliki tujuan, maksud, serta fungsi yang sama dengan versi WHO, serta memiliki sensitivitas terhadap perubahan gejala pada penderita BPH dari sebelum dan setelah menjalani TURP.
\end{abstract}

Kata kunci: IPSS, LUTS, validasi, BPH 
Kelenjar prostat adalah organ genitalia pria yang terletak di sebelah inferior buli-buli, di depan rektum dan membungkus uretra posterior. Kelenjar prostat memiliki berat normal \pm 20 gram pada orang dewasa. Kelainan yang sering dijumpai pada prostat ialah benign prostate hyperplasial yaitu pembesaran jinak dari kelenjar prostat. Penyebab BPH tidak diketahui secara jelas, tetapi beberapa hipotesis menyebutkan bahwa BPH terkait erat dengan peningkatan kadar dihidrotestoteron (DHT) dan proses penuaan. ${ }^{1,2}$

Lower urinary tract symptoms (LUTS) yang disebabkan oleh $\mathrm{BPH}$ sering terjadi pada laki-laki usia lanjut. ${ }^{3,4}$ Prevalensi BPH sendiri semakin meningkat seiring dengan meningkatnya usia, yaitu $50 \%$ pada usia 60 tahun hingga mencapai $88 \%$ pada usia 80 tahun. ${ }^{2,5}$ BPH dengan gejala LUTS-nya dapat mengakibatkan kualitas hidup seseorang menurun dan kurang produktif. ${ }^{6}$ Adanya kebutuhan untuk mengukur gejalagejala tersebut demi memfasilitasi pengambilan keputusan dalam pengobatan dan tindak lanjut dalam praktek klinik maupun dalam penelitian, mendorong badan konsultasi BPH yang disponsori oleh WHO merekomendasikan penggunaan IPSS International Prostate Symptom Score sebagai instrumen untuk mengukur gejalagejala tersebut. ${ }^{4,6}$ Hingga saat ini IPSS sudah diterjemahkan dalam berbagai bahasa terutama di Eropa. ${ }^{6}$ Beberapa versi IPSS yang diterjemahkan tersebut telah divalidasi untuk memastikannya memiliki arti dan maksud yang sama dengan IPSS versi bahasa Inggris Amerika yang dibuat oleh American Urological Association (AUA) Practice Guidelines Committee.

IPSS versi bahasa Indonesia (IPSSIna) sudah banyak digunakan di berbagai rumah sakit di Indonesia untuk membantu pengambilan keputusan dalam tatalaksana BPH. ${ }^{6}$ Demikian pula dengan berbagai rumah sakit di daerah Manado, terlebih khusus di RSUP Prof. Dr. R. D. Kandou Manado. Namun demikian, sampai saat ini belum ada penelitian yang memvalidasi IPSS versi bahasa Indonesia di daerah Manado, khususnya pada penderita BPH di
RSUP Prof. Dr. R. D. Kandou Manado. Validasi IPSS versi bahasa Indonesia perlu dilakukan untuk menjamin bahwa IPSS yang digunakan di RSUP Prof. Dr. R. D. Kandou Manado memiliki arti, maksud, dan kualitas yang sama dengan IPSS versi bahasa Inggris.

Mengacu pada uraian di atas maka perlu dilakukan penelitian untuk memvalidasi IPSS versi bahasa Indonesia sehingga dapat membantu untuk mengevaluasi gejalagejala yang berhubungan dengan BPH dan manajemen pasien serta dapat menjadi instrumen penelitian yang penting secara nasional maupun internasional. Dengan diketahuinya validitas IPSS versi bahasa Indonesia, maka dokter spesialis bedah serta para dokter dan tenaga kesehatan lainnya di Indonesia lebih yakin mengevaluasi dan mengambil keputusan dalam tatalaksana BPH dengan menggunakan IPSS versi bahasa Indonesia.

\section{METODE PENELITIAN}

Penelitian dilakukan dengan memberikan kuesioner IPSS versi bahasa Indonesia (IPSS-Ina) kepada dua kelompok subyek, yaitu kelompok uji dan kelompok kontrol. Pembagian kuesioner kepada kedua kelompok dilakukan di Poliklinik Urologi RSUP Prof. Dr. R. D. Kandou Manado. Masa pembagian kuesioner dilakukan pada bulan Juni 2018 sampai September 2018.

Validitas IPSS diuji dengan mengorelasikan hasil skor IPSS-Ina yang didapat dengan skor kualitas hidup (Quality of Life) subjek. Reliabilitas dari IPSS-Ina juga akan diuji melalui dua cara yaitu dengan uji konsistensi internal dan uji test-retest pada kelompok subyek. Uji konsistensi internal didapatkan dengan menghitung nilai koefisien Cronbach $\alpha$ dari kuesioner IPSS-Ina. Batasan nilai koefisien Cronbach $\alpha$ berkisar dari 0 (sangat tidak reliabel) hingga 1 (sangat reliabel). Pada umumnya nilai di atas 0,8 menunjukkan tingkat reliabilitas yang cukup baik dan dapat diterima. Pada uji test-retest dilakukan analisis terhadap nilai skor IPSS-Ina kelompok subjek saat pemeriksaan awal dengan hasil skor subjek yang sama saat 1 minggu setelah pemerik- 
saan awal. Reliabilitas test-retest dilakukan dengan menilai intraclass correlation coefficient (ICC), yang juga memiliki batasan nilai 0 (sangat tidak reliabel) hingga 1 (sangat reliabel).

\section{HASIL PENELITIAN}

Pada penelitian yang dilakukan di Poliklinik Urologi RSUP BLU Prof. DR. R. D. Kandou Manado selama bulan Juni 2018 sampai dengan September 2018 didapatkan sebanyak 50 subjek, dengan 25 pasien BPH sebagai kelompok uji dan 25 pasien sebagai kelompok kontrol. Rerata usia kelompok uji menunjukkan usia yang lebih tua yaitu 57,28 tahun dengan usia termuda 46 tahun dan tertua 67 tahun, dibandingkan dengan rerata usia kelompok kontrol, yaitu 39,60 tahun dengan usia termuda 21 tahun dan tertua 51 tahun (Tabel 1).

Tabel 1. Karakteristik usia subjek penelitian

\begin{tabular}{cccccc}
\hline Kelompok & $\begin{array}{c}\text { Jumlah } \\
\text { subyek }\end{array}$ & $\begin{array}{c}\text { Minimum } \\
\text { (tahun) }\end{array}$ & $\begin{array}{c}\text { Maksimum } \\
\text { (tahun) }\end{array}$ & $\begin{array}{c}\text { Median } \\
\text { (tahun) }\end{array}$ & $\begin{array}{c}\text { Rerata } \\
\text { (tahun) }\end{array}$ \\
\hline Kelompok uji & 25 & 46 & 67 & 59,00 & 57,28 \\
Kelompok kontrol & 25 & 21 & 51 & 41,00 & 39,60 \\
Total & 50 & 21 & 67 & 49,50 & 48,44 \\
\hline
\end{tabular}

Berdasarkan hasil uji korelasi Pearson, ternyata semua nilai korelasi memiliki nilai $P<0,05$ (Tabel 2). Jadi ke delapan pertanyan yang terdapat dalam IPSS-Ina yang digunakan pada pasien yang belum mendapatkan terapi Trans Uretral Resection Prostate (TURP) dan diterjemahkan dalam bahasa Indonesia ialah valid. Hasil pengujian data reabilitas menggunakan uji Cronbach memperlihatkan ke delapan pertanyaan ini memiliki reliabilitas sebesar 0,93, yang berarti ke delapan pertanyaan skoring BPH dari WHO yang diterjemahkan ke dalam bahasa Indonesia memiliki konsisten internal yang sangat tinggi.

Tabel 2. Nilai korelasi dan kemaknaan berdasarkan hasil uji Pearson sebelum TURP pada kelompok uji

\begin{tabular}{ccc}
\hline Pertanyaan & Nilai $\mathbf{r}$ & Kemaknaan \\
\hline Q1 &, 785 & $<0,001$ \\
Q2 &, 875 & $<0,001$ \\
Q3 &, 903 & $<0,001$ \\
Q4 &, 832 & $<0,001$ \\
Q5 &, 812 & $<0,001$ \\
Q6 &, 807 & $<0,001$ \\
Q7 &, 721 & $<0,001$ \\
Q8 &, 901 & $<0,001$ \\
\hline
\end{tabular}

Berdasarkan hasil uji korelasi Pearson ternyata semua nilai korelasi memiliki nilai $P<0,05$ (Tabel 3). Jadi ke delapan pertanyaan yang terdapat dalam IPSS-Ina yang digunakan pada pasien yang telah mendapatkan terapi TURP dan diterjemahkan dalam bahasa Indonesia ialah valid. Hasil pengujian data reabilitas menggunakan uji Cronbach memperlihatkan ke delapan pertanyaan ini memiliki reliabilitas sebesar 0,77, yang berarti ke delapan pertanyaan skoring BPH dari WHO yang diterjemahkan ke dalam bahasa Indonesia memiliki konsisten internal yang tinggi.

Tabel 3. Uji korelasi Pearson setelah TURP pada kelompok uji

\begin{tabular}{ccc}
\hline Pertanyaan & Nilai r & Kemaknaan \\
\hline Q21 &, 388 & $<0,001$ \\
Q22 &, 870 & $<0,001$ \\
Q23 &, 339 & $<0,001$ \\
Q24 &, 145 & $<0,001$ \\
Q25 &, 790 & $<0,001$ \\
Q26 &, 769 & $<0,001$ \\
Q27 &, 761 & $<0,001$ \\
Q28 &, 693 & $<0,001$ \\
\hline
\end{tabular}

Pengujian perbedaan skor IPSS sebelum dan setelah terapi pada kelompok uji 
dengan uji Shapiro-Wilk mendapatkan data besarnya perubahan TURP pada kelompok uji menyebar normal $(P=0,239)$. Selanjutnya perbedaan TURP sebelum dan setelah terapi diuji dengan uji t berpasangan yang mendapatkan $\mathrm{t}=11,221 \quad(P<0,001)$ yang menyatakan terdapat perbedaan sangat bermakna dari TURP sebelum dan setelah terapi pada kelompok uji (Gambar 1).

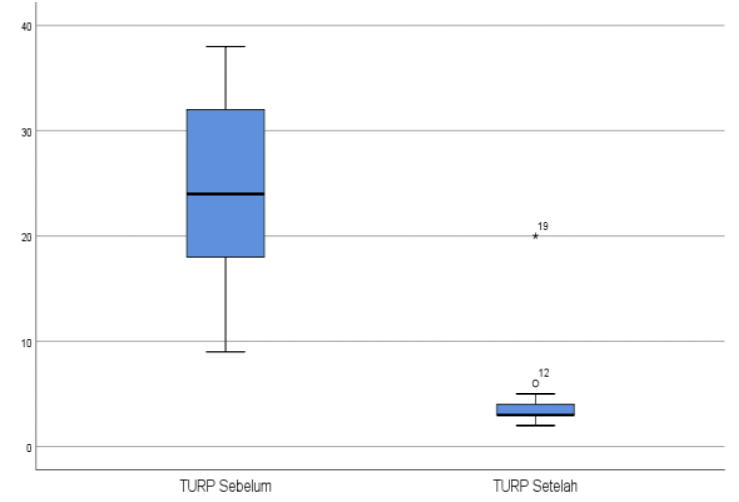

Gambar 1. Perbedaan sebaran sebelum dan setelah TURP pada kelompok uji

\section{BAHASAN}

Penelitian ini dilakukan di Poliklinik Urologi RSUP Prof. Dr. R. D. Kandou Manado selama bulan Juni 2018 sampai dengan September 2018. Sebanyak 50 subjek dilibatkan dalam penelitian ini, dengan 25 pasien BPH sebagai kelompok uji dan 25 subjek sebagai kelompok kontrol. Rerata usia kelompok BPH menunjukkan usia yang lebih tua yaitu 57,28 tahun dengan usia termuda 46 tahun dan tertua 67 tahun, dibandingkan dengan rerata usia kelompok kontrol, yaitu 39,60 tahun dengan usia termuda 21 tahun dan tertua 51 tahun (Tabel 1).

Validitas IPSS-Ina diuji dengan mengorelasikan hasil skor IPSS yang didapat dengan skor kualitas hidup (Quality of Life) subjek sedangkan reliabilitas dari IPSS-Ina juga diuji melalui dua cara yaitu dengan uji konsistensi internal dan uji testretest pada kelompok subyek. Uji konsistensi internal didapatkan dengan menghitung nilai koefisien Cronbach $\alpha$ dari kuesioner IPSS-Ina.

Berdasarkan hasil uji korelasi Pearson pada data IPSS-Ina sebelum TURP, ter- nyata semua nilai korelasi memiliki nilai $P$ $<0,05$. Jadi kedelapan pertanyan yang terdapat dalam IPSS-Ina yang digunakan menunjukkan korelasi yang kuat. Skor IPSS-Ina terbukti terkait erat dengan dengan kualitas hidup yang dirasakan subjek penelitian, Semakin berat gejala yang dirasakan semakin rendah pula kualitas hidup. Hal ini menunjukkan bahwa IPSS-Ina cukup valid untuk menilai gejalagejala LUTS. Hasil pengujian data reliabilitas menggunakan uji Cronbach mendapatkan ke delapan pertanyaan ini memiliki reliabilitas sebesar 0,93, yang berarti ke delapan pertanyaan skoring $\mathrm{BPH}$ dari WHO yang diterjemahkan ke dalam bahasa Indonesia memiliki konsisten yang sangat tinggi.

Berdasarkan hasil uji korelasi Pearson pada data subyek setelah TURP, ternyata semua nilai korelasi memiliki nilai $P<0,05$. Jadi ke delapan pertanyan yang terdapat dalam IPSS-Ina yang digunakan pada pasien yang telah mendapatkan terapi TURP dan diterjemahkan dalam bahasa Indonesia ialah valid. Hasil pengujian data reliabilitas menggunakan uji Cronbach, ke delapan pertanyaan ini memiliki reliabilitas sebesar 0,77 yang berarti ke delapan pertanyaan skoring $\mathrm{BPH}$ dari WHO yang diterjemahkan ke dalam bahasa Indonesia memiliki konsisten yang sangat tinggi. Nilai ini lebih rendah jika dibandingkan dengan nilai korelasi antara IPSS versi original (bahasa Inggris Amerika) yang dilakukan Gregoire et $\mathrm{al}^{6}$ saat memvalidasi IPSS versi original pada populasi Perancis yang mendapatkan nilai 0,86 . Nilai ini juga lebih rendah dari hasil penelitian Akilov et $\mathrm{al}^{7}$ pada populasi Uzbekiztan yang mendapatkan nilai 0,82 , namun hampir sama jika dibandingkan penelitian pada populasi di Cina oleh Choi et $\mathrm{al}^{8}$ yang mendapatkan nilai 0,71 untuk reliabilitas.

Sensitivitas terhadap perubahan IPSSIna diuji dengan melakukan komparasi skor IPSS-Ina pada kelompok uji sebelum menjalani tindakan TURP dengan skor IPSSIna pada subjek yang sama 30 hari setelah tindakan TURP. Pada kelompok uji sebelum dan setelah TURP, hasil uji kenor- 
malan Shapiro-Wilk terhadap besarnya perubahan pada kelompok uji mendapatkan data tersebar normal $(P=0,239)$. Hasil ini hampir serupa dengan penelitian dari Badia et $\mathrm{al}^{9}$ yang memperoleh hasil sebesar 2,52 untuk sensitivitas dari IPSS.

Karena hasil pengujian kenormalan besarnya perubahan TURP pada kelompok uji menyebar normal, maka perbedaan sebelum dan setelah TURP diuji dengan uji $\mathrm{t}$ berpasangan yang mendapatkan $\mathrm{t}=11,221$ dengan $P<0,0001$. Hasil uji ini menyatakan terdapat perbedaan sangat bermakna sebelum dan setelah TURP pada kelompok uji, yang menunjukkan bahwa IPSS-Ina dapat dipahami dengan mudah oleh subjek sehingga dapat memberikan hasil yang sesuai dengan gejala yang dialami.

\section{SIMPULAN}

International Prostate Symptom Score (IPSS) versi bahasa Indonesia terbukti memiliki validitas dan reliabilitas yang sangat baik terhadap masyarakat di Manado, sehingga dapat dijamin memiliki tujuan, maksud, serta fungsi yang sama dengan versi WHO.

International Prostate Symptom Score (IPSS) versi bahasa Indonesia, memiliki sensitivitas terhadap perubahan gejala pada penderita BPH dari sebelum dan setelah menjalani TURP.

\section{DAFTAR PUSTAKA}

1. Tanagho EA, McAninch JW. Neoplasms of the prostate gland. Smith's General Urology (17th ed). USA: McGraw-Hill Companies, Inc, 2008; p. 348-54.

2. Roehrborn CG. Benign prostatic hyperplasia: etiology, pathophysiology, epidemiology, and natural history. In: Wein AJ , editor. Campbell-Walsh Urology (10th ed). Philadelphia: Saunders, 2012; p. 2555-609.

3. Chapple C, Abrams P, editors. Male Lower Urinary Tract Symptoms (LUTS). An International Consultation on Male LUTS. Fukuoka: Societe Internationale d'Urologie (SIU), 2012; p. 21, 42, 333.

4. Parsons JK, Mougey J, Lambert L, Wilt TJ, Fink HA, Garzotto M, et al. Lower urinary tract symptoms increase the risk in older men. BJU Int. 2009;104(1):638.

5. Monoarfa RA, Mochtar CA. Validation of Indonesia version of IPSS. Indonesian Journal of Urology. 2014;21(1).

6. Gregoire JP, Moisan J, Labrecque M, Cusan L DP. Validation of a French adaptation of the international prostatic symptom score. Prog Urol. 1996; 6(2): 240-9.

7. Akilov FA, Arustamov DL, RAkhmonov OM, Alidjanov JF. The validation IPSS questionnaire in a Uzbeklanguage population. 2012; e222. Available from: https://www.research gate.net/.../265846938_The validation_of_IPSS_International_Pro

8. Choi EPH, Lam CLK, Chin WY. Validation of the international prostate symptom score in Chinese males and females with lower urinary tract symptoms. Health Qual Life Outcomes. 2014;12:1.

9. Badia X, Garcia-Losa M, Dal-Re R, Carballido JSM, Serra M. Validation of a harmonized Spanish version of the IPSS: evidence of equivalence with the original American scale. International Prostate Symptom Score. Urology. 1998;52(4):614-20. 